various aspects of ovarian function, Sir Solly Zuckerman defends the thesis that oogenesis is a process that comes to an end at, or about the time of, birth, and deals critically with recent observations which purport to resuscitate the other view that neoformation continues into adult life, while Dr. Williams and Dr. Rowlands discuss the life, growth and fate of the large ovarian follicles and the corpus luteum respectively. Other mainly endocrinological contributions describe experiments concerned with such diverse subjects as the tissue culture of fœtal repro. ductive tracts and the study of the human testis with the electron microscope. The placenta is an excellent example of a transient tissue, and a further group of papers describe the morphological and biochemical ehanges in the organ during pregnancy. Dr. Villee thought that there was no evidence for any senile chenge in function which could be used to explain the onset of labour, and felt that the placenta was still quite active metabolically at the end of its life. A comparable conclusion came from Prof. Huggett, "that there is evidence that its 'efficiency', certainly for some functions, is increased in its old age; in fact, it might be said to be abruptly expelled in the prime of life".

Other papers by Dr. Mollison and Dr. Lovelock discuss what happens to the red blood cells to bring their life to such a rapid end, and what could be done to prolong their survival in storage. Age changes in the sweat glands of the human female, the factors controlling growth of the antlers in deer, and finally a botanical paper on the metabolism of senescent leaves, are titles which give some indication that, on this occasion, the limits of the definition of ageing were very widely stretched, perhaps to the extent of causing a lack of cohesion in the contents of the volume.

Contributors to the third colloquium on the "Methodology of the Study of Ageing" related their papers more closely to a single general theme. The study of ageing is of such relatively recent scientific respectability that workers in the field are acutely conscious of the need to agree on the basic definitions of their subject and on the limitations of various methods for studying the problem. At present they are more aware of the needs than confident that they have found solutions. It is clear that no one was sure about the level of organization at which ageing can be studied most profitably. Some thought that the comparative approach in studying whole populations had been badly neglected, whereas others discussed the ways in which ageing in separate organ systems or in individual cells might provide the important clues. Clinicians at the meeting were perhaps unnecessarily humble in believing that studies on human beings were less likely to be valuable than those of experimental workers on the mouse or the hamster.

The latter part of Volume 3 is taken up with a discussion of the psychological aspects of ageing and is notable for an excellent account by Welford of the problems which face those who want to understand the reasons why the work performance of human beings changes as they get older. Much of what he had to say about the design of experimental studies in psychological problems is very relevant to the design of experiments on animals for other gerontological purposes.

"The Biology of Ageing" summarizes the contributions to a symposium, organized by the Institute of Biology, which was intended for a much wider audience than is to be found at the Ciba Foundation.
The papers cover all aspects of ageing from the demographic aspects in human populations to ageing in bacteria and higher plants. Several of the authors whose papers appear in the Ciba Colloquia are also represented in this volume, and some of them say little that they have not said elsewhere. The volume does, however, bring together contributions which should satisfy the many non-specialists who want to know how the subject is developing without wishing to immerse themselves in the details of experimental work which are to be found in the Cibs Colloquia.

P. L. KROHN

\section{CHEMISTRY AND LIFE}

A Symposium on the Chemical Basis of Heredity Edited by William D. MeElroy and Bentley Glass. (Sponsored by the McCollum-Pratt Institute of the Johns Hopkins University, with support from the Atomic Energy Commission.) Pp. xiv +848 , (Baltimore, Md.: The Johns Hopkins Press; London : Oxford University Press, 1957.) £5 net.

7 HIS book describes in great detail the remarkable discussion of the chemical basis of heredity held in $\mathbf{1 9 5 6}$ at the Johns Hopkins Institute. Almost every aspect of the problem of heredity was discussed and the very wide extent of the matters under survey is shown by the fact that Dr. Bentley Glass occupies no less than 77 pages in his summary of the whole symposium.

Original work is described in eight chapters which are subdivided into sections with the various discussions within the sections. The chapters concern "Cellular Units of Heredity", "The Role of the Nucleus", "Nucleic Acids and Associated Structures in Cell Division and Protein Synthesis", "Nucleic Acids -as Transforming Agents", "Viruses as Bearers of Heritable Characteristics", "Nucleic Acids-Chemical Composition and Structure", "Synthesis of Nucleotides and Nucleic Acids" and "Mechanism of Duplica. tion". In this book all the papers are written with great clarity and are frequently illustrated by photographs and diagrams. For special mention one would point to the discussions on the nucleus and on the synthesis of proteins, the various aspects of nucleic acids as transforming agents, where the most astonishing discoveries are being made, and the outstanding work of Fraenkel-Conrat and his colleagues on the nature of viruses reconstituted from protein and nucleic acids. In addition there are discussions on the structure of deoxyribonucleic acid, particularly the Crick-Watson double helix, the polynucleotide biosynthesis of Ochos and the biosynthesis of nucleic acids in some microbial systems. Delbruck's mechan. ism of deoxyribonucleic acid replication and the molecular basis of genetic recombination in phage are both remarkably good chapters.

The discussions of the various papers have been well recorded and form some of the most interesting reading in the book. From this conference it is apparent how much structural and physical chemistry are adding to knowledge of the biology of genes, chromosomes and studies in heredity generally.

The organizers of the symposium are to be congratulated on getting together such a wealth of talent; and the authors have done an excellent job in inter. preting their ideas and latest discoveries. Every geneticist and biochemist will need to possess this book.
M. StaCey 